\title{
Variation in regulator of G-protein signaling 17 gene (RGS17) is associated with multiple substance dependence diagnoses
}

\author{
Huiping Zhang ${ }^{1,4^{*}}$, Fan Wang ${ }^{1,4}$, Henry R Kranzler ${ }^{5}$, Raymond F Anton ${ }^{6}$ and Joel Gelernter ${ }^{1,2,3,4}$
}

\begin{abstract}
Background: RGS17 and RGS20 encode two members of the regulator of G-protein signaling RGS-Rz subfamily. Variation in these genes may alter their transcription and thereby influence the function of $G$ protein-coupled receptors, including opioid receptors, and modify risk for substance dependence.

Methods: The association of 13 RGS17 and eight RGS20 tag single nucleotide polymorphisms (SNPs) was examined with four substance dependence diagnoses (alcohol (AD), cocaine (CD), opioid (OD) or marijuana (MjD)] in 1,905 African Americans (AAs: 1,562 cases and 343 controls) and 1,332 European Americans (EAs: 981 cases and 351 controls). Analyses were performed using both $x^{2}$ tests and logistic regression analyses that covaried sex, age, and ancestry proportion. Correlation of genotypes and mRNA expression levels was assessed by linear regression analyses.
\end{abstract}

Results: Seven RGS17 SNPS showed a significant association with at least one of the four dependence traits after a permutation-based correction for multiple testing (0.003 $\left.\leq P_{\text {empirical }} \leq 0.037\right)$. The $G$ allele of SNP rs596359, in the $R G S 17$ promoter region, was associated with $\mathrm{AD}, \mathrm{CD}, \mathrm{OD}$, or $\mathrm{MjD}$ in both populations $\left(0.005 \leq P_{\text {empirical }} \leq 0.019\right)$. This allele was also associated with significantly lower mRNA expression levels of RGS17 in YRI subjects $(P=0.002)$ and non-significantly lower mRNA expression levels of RGS17 in CEU subjects $(P=0.185)$. No RGS20 SNPs were associated with any of the four dependence traits in either population.

Conclusions: This study demonstrated that variation in RGS17 was associated with risk for substance dependence diagnoses in both AA and EA populations.

Keywords: RGS17 and RGS20, Multiple substance dependence, Genetic association, Haplotype analysis, Regression analysis, Genotype-expression relationship

\section{Background}

Substance (alcohol or drug) dependence (SD) is a set of complex disorders influenced by gene-gene and gene-environment interactions. Genes involved in dopaminergic, serotonergic, GABAergic, glutamatergic, cannabinoid, and opioidergic systems have been implicated in SD risk. Mounting evidence suggests that variation in genes coding for dopamine, serotonin, GABA, glutamate, cannabinoid, and opioid receptors may increase vulnerability to SD and related phenotypes [1-4]. The function of

\footnotetext{
* Correspondence: huiping.zhang@yale.edu

'Departments of Psychiatry, Yale University School of Medicine, New Haven, $\mathrm{CT}$, USA

${ }^{4}$ VA Connecticut Healthcare System, West Haven, CT, USA

Full list of author information is available at the end of the article
}

these receptors, which belong to a large $G$ proteincoupled receptor (GPCR) family, is regulated by regulators of G-protein signaling proteins (RGSs) $[5,6]$.

Members of the RGS family are functionally related to selective GPCR signal transduction pathways [7]. For example, they participate in opioid receptor desensitization, internalization, recycling and degradation $[8,9]$. In analyzing the function of RGS17 in mouse brain, Garzon et al. [10] found that, when RGS17 expression was reduced, the $\mu$-opioid receptor (MOR)-mediated antinociceptive response to morphine and $\left[\mathrm{D}-\mathrm{Ala}^{2}, \mathrm{~N}-\mathrm{MePhe}^{4}\right.$, Gly-ol ${ }^{5}$ ]-enkephalin (DAMGO) was increased. Ajit et al. [11] demonstrated that RGS17 interacted with protein kinase $\mathrm{C}$ interacting protein (PKCI-1) and modulated the

\section{Biomed Central}

(c) 2012 Zhang et al.; licensee BioMed Central Ltd. This is an Open Access article distributed under the terms of the Creative Commons Attribution License (http://creativecommons.org/licenses/by/2.0), which permits unrestricted use, distribution, and reproduction in any medium, provided the original work is properly cited. 
signaling pathway of the MOR. Moreover, in membranes from periaqueductal gray matter (PAG), both RGS17 and RGS20 co-precipitated with the MOR [10]. By use of intraventricular administration of antisense oligonucleotides, Garzon et al. [12] demonstrated that a suppression of RGS20 expression in mouse brain greatly increased the supraspinal antinociceptive effect of the MOR agonists. Together, these findings indicate that GPCRs (e.g., MOR) are functionally linked to RGS proteins (e.g., RGS17 and RGS20).

RGS 17 and RGS20 are two members of the RGS-Rz subfamily. They are closely related to opioid receptors in both chromosomal location and cellular function. The RGS17 gene (RGS17) is linked to the $\mu$-opioid receptor (MOR) gene (OPRM1) on chromosome 6 (distance: about $0.9 \mathrm{Mb}$ ), and the RGS20 gene (RGS20) is linked to the $\mathrm{k}$-opioid receptor (KOR) gene (OPRK1) on chromosome 8 (distance: about $0.6 \mathrm{Mb}$ ) [6]. Close genomic proximity may reflect a coordinated transcription of the linked genes or a shared regulatory mechanism for their expression [9]. In other words, the transcription of $R S G$ 17 (or RGS20) may influence the transcription of OPRM1 (or OPRK1) and vice versa. Genomic proximity may also reflect a functional relationship between the RGS-Rz proteins (RGS17 and RGS20) and opioid receptors.

Several studies, including ours, have shown a positive association between variation at OPRM1 [13-17] and OPRK1 [18,19] and alcohol or drug dependence, although negative results have been reported [20]. Additionally, mouse genome scans have mapped a quantitative trait locus (QTL) for morphine preference to the $\mu$-opioid receptor gene region (where RGS17 is located) [21] and a QTL for alcohol consumption to the K-opioid receptor gene region (where RGS20 is located) [22]. Considering the close relationship between the RGS-Rz proteins and opioid receptors, and the association between opioid receptor genes and alcohol or drug dependence, we hypothesized that variation in RGS17 and RGS20 could affect vulnerability to various SD types. To date, no published studies have examined the association between RGS17 and RGS20 polymorphisms and SD or other psychiatric disorders, although associations between RGS2 variants and anxiety [23,24] and between RGS4 variants and schizophrenia [25,26] have been reported. We used a case-control association study approach to analyze the association of RGS17 and RGS20 variants and risk for four different SD diagnoses. We also examined the correlation between genotypes of SDassociated variants and gene expression levels.

\section{Methods}

\section{Recruitment and ascertainment}

Unrelated case and control subjects were recruited from substance abuse treatment centers and through advertisements at the University of Connecticut Health Center $(n=1,394)$, Yale University School of Medicine (APT foundation) $(n=1,256)$, the University of Pennsylvania School of Medicine $(n=304)$, and the Medical University of South Carolina $(n=283)$. Subjects gave informed consent as approved by the institutional review board at each clinical site, and certificates of confidentiality were obtained from the National Institute on Drug Abuse and the National Institute on Alcohol Abuse and Alcoholism. All subjects were interviewed using an electronic version of the Semi-Structured Assessment for Drug Dependence and Alcoholism (SSADDA) [27] to derive diagnoses for lifetime alcohol, cocaine, opioid or marijuana dependence $(\mathrm{AD}, \mathrm{CD}, \mathrm{OD}$ or $\mathrm{MjD}$, respectively) according to DSM-IV criteria [28]. Control subjects were screened to exclude individuals with any of these four SD traits. Additionally, case and control subjects with a lifetime major psychotic disorder (schizophrenia or bipolar disorder) were excluded. The clinical characteristics (including SD comorbidity information) of participants are presented in Table 1. There were 1,562 unrelated AA cases: $\operatorname{AD}(n=1,064,68.1 \%), C D(n=1,309,83.8 \%)$, OD $(\mathrm{n}=358,22.9 \%)$ and/or $\operatorname{MjD}(\mathrm{n}=531,34.0 \%)$ and 343 unrelated AA controls. There were 981 unrelated EA cases: $\operatorname{AD}(n=671,68.4 \%), C D(n=696,70.9 \%)$, OD $(\mathrm{n}=577,58.8 \%)$ and/or $\mathrm{MjD}(\mathrm{n}=318,32.4 \%)$ and 351 EA unrelated controls.

\section{Genotyping}

Thirteen tag single nucleotide polymorphisms (SNPs) in RGS17 and eight tag SNPs in RGS20 were selected from public sources such as the NCBI dbSNP database (http://www.ncbi.nlm.nih.gov/SNP), the HapMap Genome Browser (http://www.hapmap.org), and the SNPbrowser software v 4.0 (Applied Biosystems), based upon their minor allele frequencies and linkage disequilibrium (LD) information (Table 2). The TaqMan method [29] was used to genotype SNP markers at the Yale University School of Medicine. Eight percent of genotypes were repeated for quality control; any mismatches triggered repeats of all genotypes on a given plate.

\section{Statistical analysis}

Data analysis was conducted separately in AAs and EAs based on self-reported race. To verify the self-reported race, we used a Bayesian model-based clustering method implemented in the program STRUCTURE [30] to estimate the African and European ancestry proportions of individual subjects, using genotype data from 41 ancestry informative markers (AIMs), including 36 short tandem repeat markers and five SNPs, as described previously $[31,32]$. This clustering produced two distinct groups 
Table 1 Clinical characteristics of case-control samples

\begin{tabular}{|c|c|c|c|c|}
\hline & \multicolumn{2}{|c|}{ African Americans (AAs) } & \multicolumn{2}{|c|}{ European American (EAs) } \\
\hline & SD cases $(n=1,562)$ & Contols $(n=343)$ & SD cases $(n=981)$ & Contols $(n=351)$ \\
\hline$A D, n(\%)$ & $1064(68.1 \%)$ & $0(0 \%)$ & $671(68.4 \%)$ & $0(0 \%)$ \\
\hline$C D, n(\%)$ & $1309(83.8 \%)$ & $0(0 \%)$ & $696(70.9 \%)$ & $0(0 \%)$ \\
\hline OD, n (\%) & $358(22.9 \%)$ & $0(0 \%)$ & $577(58.8 \%)$ & $0(0 \%)$ \\
\hline MjD, n (\%) & $531(34.0 \%)$ & $0(0 \%)$ & $318(32.4 \%)$ & $0(0 \%)$ \\
\hline$A D+C D+O D+M j D, n(\%)$ & $87(5.6 \%)$ & $0(0 \%)$ & $131(13.4 \%)$ & $0(0 \%)$ \\
\hline$A D+C D+O D, n(\%)$ & $196(12.5 \%)$ & $0(0 \%)$ & $283(28.8 \%)$ & $0(0 \%)$ \\
\hline$A D+O D+M j D, n(\%)$ & $90(5.8 \%)$ & $0(0 \%)$ & $141(14.4 \%)$ & $0(0 \%)$ \\
\hline$\overline{A D}+C D+M j D, n(\%)$ & $360(23.0 \%)$ & $0(0 \%)$ & $195(19.9 \%)$ & $0(0 \%)$ \\
\hline$C D+O D+M j D, n(\%)$ & $116(7.4 \%)$ & $0(0 \%)$ & $182(18.6 \%)$ & $0(0 \%)$ \\
\hline$A D+C D, n(\%)$ & $854(54.7 \%)$ & $0(0 \%)$ & $476(48.5 \%)$ & $0(0 \%)$ \\
\hline $\mathrm{AD}+\mathrm{OD}, \mathrm{n}(\%)$ & $217(13.9 \%)$ & $0(0 \%)$ & $321(32.7 \%)$ & $0(0 \%)$ \\
\hline$\overline{A D}+M j D, n(\%)$ & $424(27.1 \%)$ & $0(0 \%)$ & $232(23.6)$ & $0(0 \%)$ \\
\hline $\mathrm{CD}+\mathrm{OD}, \mathrm{n}(\%)$ & $303(19.4 \%)$ & $0(0 \%)$ & $436(44.4 \%)$ & $0(0 \%)$ \\
\hline$C D+M j D, n(\%)$ & $454(29.1 \%)$ & $0(0 \%)$ & $260(26.5 \%)$ & $0(0 \%)$ \\
\hline $\mathrm{OD}+\mathrm{MjD}, \mathrm{n}(\%)$ & $123(7.9 \%)$ & $0(0 \%)$ & $206(21.0 \%)$ & $0(0 \%)$ \\
\hline \multirow[t]{2}{*}{ Male, n (\%) } & 786 (50.5\%) & $153(44.6 \%)$ & $485(49.4 \%)$ & $190(54.1 \%)$ \\
\hline & $x^{2}=3.45, \mathrm{df}=1, P=0.0$ & & $X^{2}=1.70, d f=1, P=0$ & \\
\hline \multirow[t]{2}{*}{ Age, years } & $39 \pm 9$ & $39 \pm 9$ & $38 \pm 12$ & $41 \pm 13$ \\
\hline & $\mathrm{t}=-1.029, P=0.304$ & & $\mathrm{t}=4.76, P=2.2 \times 10^{-6}$ & \\
\hline
\end{tabular}

$S D$, substance (alcohol, cocaine, opioid, and/or marijuana) dependence.

$A D$, alcohol dependence; $C D$, cocaine dependence; $O D$, opioid dependence; $M j D$, marijuana dependence.

Symbol " + " means comorbidity.

Sex differences between cases and controls were analyzed by the Chi-square test.

Age differences between cases and controls were analyzed by the $t$-test.

that were highly concordant with self-reported AA and EA group membership. Hardy-Weinberg equilibrium (HWE) analysis was carried out in control subjects for each of the 21 RGS17 and the eight RGS20 SNPs using the Chi-square test. Allelic association analyses were performed using the Pearson's $\chi^{2}$ test. To adjust for the multiple tests performed and obtain an empirical null distribution of association test $P$ values ( $\left.P_{\text {empirical }}\right)$, we conducted 10,000 permutations in the case-control sample. The association of SNP markers and SD traits was further evaluated using the multivariate logistic regression analysis under the additive model with consideration of possible confounding factors, which were sex, age, and ancestry proportion of subjects. The CochranMantel-Haenszel (CMH) test was used to calculate the overall genetic effect of SNPs by combining data from $\mathrm{AA}$ and EA populations. The above four types of analyses were implemented using PLINK v.1.07 (http://pngu. mgh.harvard.edu/purcell/plink/) [33]. Haplotype analyses were carried out using the program Haploview v.4.2. [34]. Haplotype blocks were defined according to the criteria of Gabriel et al. [35].

\section{Bioinformatics and genotype-expression analysis}

DNA sequences harboring SNP markers that showed a significant association with SD phenotypes were queried for predicted transcription factor (TF) binding sites using the computational tool of the Transcription Element Search System (TESS, http://www.cbil.upenn.edu/cgi$\mathrm{bin} / \mathrm{tess})$. To assess the functional effect of SD-associated RGS17 and RGS2O variants on gene expression, whole genome Illumina lymphoblastoid cell line gene expression data from 120 unrelated HapMap individuals (60 from the CEU population and 60 from the YRI population) were extracted from the GSE6536 series data set in the Gene Expression Omnibus (GEO) site (http://www.ncbi.nlm.nih.gov/geo). Expression data (or mRNA levels) of RGS17 (determined by probe GI_21361404-S), RGS20 (determined by probe GI_13654234-A), and OPRM1 (determined by probe GI_4505514-S) were included in the genotype-expression association analyses. Genotype data of RGS17 and RGS2O SNPs from 60 unrelated CEU individuals and 60 unrelated YRI individuals were downloaded from the HapMap genome browser (http://www.hapmap.org/ 
Table 2 Characteristics of SNPs in RGS20 and RGS17

\begin{tabular}{|c|c|c|c|c|c|c|c|}
\hline \multirow[t]{2}{*}{ ID } & \multirow[t]{2}{*}{ SNPs } & \multirow{2}{*}{$\frac{\text { Chromosome }}{\text { Position (hg18) }}$} & \multirow[t]{2}{*}{ Gene } & \multicolumn{3}{|c|}{ Allele } & \multirow[b]{2}{*}{ MAF (EAs } \\
\hline & & & & Location & & MAF (AAs) & \\
\hline RGS17_1 & rs9397578 & 153371201 & RGS17 & 3' near gene & $A / G$ & $0.27(\mathrm{~A})$ & $0.26(A)$ \\
\hline$\overline{R G S 17 \_2}$ & rs7750874 & 153372161 & RGS17 & 3' near gene & $\mathrm{A} / \mathrm{T}$ & 0.29 (A) & $0.34(\mathrm{~A})$ \\
\hline RGS17_3 & rs503366 & 153375243 & RGS17 & Intron 4 & $\mathrm{C} / \mathrm{T}$ & $0.47(\mathrm{C})$ & 0.49 (C) \\
\hline RGS17_4 & rs610614 & 153383477 & RGS17 & Intron 4 & $\mathrm{C} / \mathrm{T}$ & $0.42(C)$ & $0.31(\mathrm{C})$ \\
\hline RGS17_5 & rs545323 & 153387002 & RGS17 & Intron 4 & $\mathrm{C} / \mathrm{T}$ & $0.05(C)$ & $0.33(\mathrm{C})$ \\
\hline RGS17_6 & rs516557 & 153395551 & RGS17 & Intron 2 & $\mathrm{C} / \mathrm{T}$ & $0.47(\mathrm{~T})$ & $0.47(C)$ \\
\hline RGS17_7 & rs9371276 & 153410854 & RGS17 & Intron 1 & $\mathrm{C} / \mathrm{T}$ & $0.48(T)$ & $0.30(C)$ \\
\hline$\overline{R G S 17 \_8}$ & rs1933258 & 153419500 & RGS17 & Intron 1 & $C / G$ & $0.49(\mathrm{G})$ & $0.3(\mathrm{C})$ \\
\hline RGS17_9 & rs9397585 & 153438568 & RGS17 & Intron 1 & $\mathrm{C} / \mathrm{T}$ & $0.49(\mathrm{C})$ & $0.37(C)$ \\
\hline RGS17_10 & rs685826 & 153452948 & RGS17 & Intron 1 & $\mathrm{C} / \mathrm{T}$ & $0.46(T)$ & $0.44(C)$ \\
\hline RGS17_11 & rs6931160 & 153472144 & RGS17 & Intron 1 & $\mathrm{C} / \mathrm{G}$ & $0.50(\mathrm{G})$ & $0.44(\mathrm{C})$ \\
\hline RGS17_12 & rs1281962 & 153473069 & RGS17 & Intron 1 & $\mathrm{C} / \mathrm{G}$ & $0.24(G)$ & $0.46(\mathrm{G})$ \\
\hline RGS17_13 & rs596359 & 153498746 & RGS17 & 5 ' near gene & $A / G$ & $0.33(\mathrm{G})$ & $0.48(\mathrm{G})$ \\
\hline RGS20_1 & rs1384797 & 54956481 & RGS20 & intron 1 & $\mathrm{~A} / \mathrm{G}$ & $0.40(\mathrm{G})$ & $0.02(\mathrm{G})$ \\
\hline RGS20_2 & rs2220093 & 54963880 & RGS20 & intron 1 & $A / G$ & $0.36(A)$ & $0.10(\mathrm{G})$ \\
\hline RGS20_3 & rs1483537 & 54980301 & RGS20 & intron 1 & $\mathrm{~A} / \mathrm{G}$ & $0.35(\mathrm{G})$ & $0.01(\mathrm{G})$ \\
\hline RGS20_4 & rs7824575 & 54984872 & RGS20 & intron 1 & $\mathrm{~A} / \mathrm{G}$ & $0.24(\mathrm{G})$ & $0.27(\mathrm{~A})$ \\
\hline RGS20_5 & rs2128821 & 55006166 & RGS20 & intron 1 & $\mathrm{C} / \mathrm{G}$ & $0.42(C)$ & $0.26(\mathrm{G})$ \\
\hline RGS20_6 & rs9298496 & 55018233 & RGS20 & intron 2 & $\mathrm{C} / \mathrm{T}$ & $0.37(C)$ & $0.34(C)$ \\
\hline RGS20_7 & rs6981243 & 55029044 & RGS20 & intron 3 & $\mathrm{~A} / \mathrm{C}$ & $0.42(\mathrm{~A})$ & $0.41(\mathrm{C})$ \\
\hline RGS20_8 & rs7009781 & 55035764 & RGS20 & downstream & $C / T$ & $0.27(\mathrm{~T})$ & $0.17(\mathrm{C})$ \\
\hline
\end{tabular}

Chromosome positions are based on Homo sapiens chromosome 6 genomic contig NT_025741.14 (RGS17) and chromosome 8 genomic contig NT_008183.18 (RGS20). MAF (AA), minor allele frequency in our African American (AA) sample; MAF (EA), minor allele frequency in our European Americans (EA) sample.

cgi-perl/gbrowse/hapmap_B36). The correlation of SNP marker genotypes and mRNA expression levels was assessed by linear regression analyses assuming an additive model and adjusted by sex.

\section{Results}

\section{Allelic association}

There were no deviations from HWE for genotype distributions of any of the 13 RGS17 and eight RGS20 SNPs in either AA or EA controls (the $P$ value for statistical significance was set at $P>0.05 / 21=0.002$ ) (data not shown). As shown in Figure 1, Table 3 and Additional file 1: Table S1, seven RGS17 SNPs showed significant association with at least one of the four SD traits after permutation-based correction for multiple testing $\left(0.003 \leq P_{\text {empirical }} \leq 0.037\right)$. Detailed information about genetic association results of 13 RGS17 SNPs, RGS17 physical position on Chromosome 6 , and recombination rate in the gene region is presented in Additional file 1: Figures S1 and S2. SNP rs596359 (in the promoter region) was associated with $\mathrm{AD}, \mathrm{CD}, \mathrm{OD}$ and $\mathrm{MjD}$ in both AAs and EAs $\left(0.005 \leq P_{\text {empirical }} \leq 0.019\right)$. Six other SNPs (rs6931160 in Intron 1, rs9397585 in Intron 1, rs1933258 in Intron 1, rs9371276 in Intron 1, rs516557 in Intron 2 and rs545323 in Intron 4) were associated with one or more of these four SD traits in AAs and/or EAs $\left(0.003 \leq P_{\text {empirical }} \leq 0.037\right)$. Logistic regression analyses using sex, age and ancestry proportion as covariates confirmed the association of the seven RGS17 SNPs with multiple SD traits in AAs and/or EAs $\left(0.002 \leq P_{a d-}\right.$ justed $\leq 0.053$ ) (Table 3). Combining data from both AAs and EAs via meta-analysis showed that five RGS17 SNPs (rs596359, rs6931160, rs1933258, rs9371276, and rs545323) were associated with at least one of the four SD traits $\left(1.7 \times 10^{-4} \leq P_{\text {meta }} \leq 0.045\right)$. None of the eight RGS20 SNPs was associated with any of the four SD traits in either AAs or EAs (Figure 1 and Additional file 1: Table S2).

\section{Haplotype association}

The association of RGS17 variants with SD was further analyzed using the haplotype association analysis approach. As shown in Figure 2, RGS17 SNPs were located in three haplotype blocks (I, II, and III) (Block II harbors three SNPs in AAs but four SNPs in EAs). Table 4 lists the haplotypes that were associated with one or more of the SD phenotypes $\left(P_{\text {observed }} \leq 0.05\right)$. In AAs, two haplotypes (GATTC and GTTCT) comprised of alleles of five 
Table 3 Association of seven RGS17 SNPs and four substance dependence (SD) Traits

\begin{tabular}{|c|c|c|c|c|c|c|c|c|c|c|}
\hline SNPs & Trait & Race & RA & Frequency & $x^{2}$ & $P_{o b s}$ & OR $(95 \% \mathrm{Cl})$ & $P_{a d j}$ & OR $(95 \% \mathrm{Cl})$ & $P_{e m p}$ \\
\hline \multirow[t]{4}{*}{ rs545323 } & $A D$ & $\mathrm{AA}$ & C & $0.06 \backslash 0.03$ & 6.70 & 0.010 & $1.96(1.17-3.30)$ & 0.013 & $1.96(1.16-3.32)$ & 0.010 \\
\hline & $C D$ & AA & C & $0.05 \backslash 0.03$ & 6.74 & 0.009 & $1.95(1.17-3.25)$ & 0.015 & $1.95(1.16-3.28)$ & 0.009 \\
\hline & OD & $\mathrm{AA}$ & $C$ & $0.07 \backslash 0.03$ & 11.27 & 0.001 & $2.55(1.45-4.49)$ & 0.002 & $2.51(1.41-4.46)$ & 0.003 \\
\hline & MjD & $\mathrm{AA}$ & C & $0.06 \backslash 0.03$ & 7.30 & 0.007 & $2.10(1.21-3.64)$ & 0.009 & $2.10(1.20-3.67)$ & 0.009 \\
\hline rs516557 & $A D$ & $\mathrm{AA}$ & $\mathrm{T}$ & $0.49 \backslash 0.43$ & 4.78 & 0.029 & $1.25(1.02-1.52)$ & 0.035 & $1.23(1.02-1.50)$ & 0.018 \\
\hline \multirow[t]{2}{*}{ rs9371276 } & OD & EA & $C$ & $0.33 \backslash 0.27$ & 7.47 & 0.006 & $1.34(1.09-1.66)$ & 0.008 & $1.33(1.08-1.63)$ & 0.008 \\
\hline & $\mathrm{MjD}$ & EA & C & $0.33 \backslash 0.27$ & 5.11 & 0.024 & $1.32(1.04-1.62)$ & 0.053 & $1.26(1.00-1.58)$ & 0.032 \\
\hline \multirow[t]{3}{*}{ rs1933258 } & $C D$ & EA & $C$ & $0.31 \backslash 0.27$ & 4.54 & 0.033 & $1.25(1.02-1.54)$ & 0.04 & $1.25(1.01-1.54)$ & 0.037 \\
\hline & OD & EA & $C$ & $0.33 \backslash 0.27$ & 8.51 & 0.004 & $1.37(1.11-1.70)$ & 0.004 & $1.36(1.10-1.68)$ & 0.005 \\
\hline & MjD & EA & $C$ & $0.33 \backslash 0.27$ & 5.63 & 0.018 & $1.34(1.05-1.70)$ & 0.036 & $1.29(1.02-1.63)$ & 0.024 \\
\hline \multirow[t]{2}{*}{ rs9397585 } & OD & EA & C & $0.40 \backslash 0.35$ & 4.39 & 0.036 & $1.24(1.01-1.51)$ & 0.02 & $1.27(1.04-1.56)$ & 0.028 \\
\hline & MjD & EA & C & $0.41 \backslash 0.35$ & 4.36 & 0.037 & $1.27(1.02-1.59)$ & 0.035 & $1.28(1.02-1.61)$ & 0.030 \\
\hline \multirow[t]{3}{*}{ rs6931160 } & $\mathrm{MjD}$ & $\mathrm{AA}$ & $\mathrm{G}$ & $0.47 \backslash 0.53$ & 6.35 & 0.012 & $0.78(0.64-0.95)$ & 0.015 & $0.79(0.65-0.95)$ & 0.016 \\
\hline & OD & EA & $C$ & $0.48 \backslash 0.42$ & 5.14 & 0.023 & $1.25(1.03-1.51)$ & 0.019 & $1.26(1.04-1.54)$ & 0.018 \\
\hline & $C D$ & $\mathrm{AA}$ & G & $0.49 \backslash 0.53$ & 4.56 & 0.033 & $0.83(0.7-0.99)$ & 0.036 & $0.83(0.70-0.99)$ & 0.028 \\
\hline \multirow[t]{8}{*}{ rs596359 } & $A D$ & $\mathrm{AA}$ & G & $0.35 \backslash 0.29$ & 7.82 & 0.005 & $1.31(1.08-1.58)$ & 0.008 & $1.29(1.07-1.56)$ & 0.005 \\
\hline & $A D$ & EA & G & $0.50 \backslash 0.44$ & 6.37 & 0.012 & $1.27(1.05-1.52)$ & 0.011 & $1.27(1.06-1.53)$ & 0.014 \\
\hline & $C D$ & $\mathrm{AA}$ & G & $0.34 \backslash 0.29$ & 6.77 & 0.009 & $1.28(1.06-1.54)$ & 0.011 & $1.27(1.06-1.53)$ & 0.009 \\
\hline & $C D$ & EA & G & $0.51 \backslash 0.44$ & 6.91 & 0.009 & $1.28(1.06-1.54)$ & 0.008 & $1.29(1.07-1.56)$ & 0.006 \\
\hline & OD & $\mathrm{AA}$ & G & $0.35 \backslash 0.29$ & 6.50 & 0.011 & $1.34(1.07-1.69)$ & 0.023 & $1.31(1.04-1.63)$ & 0.019 \\
\hline & OD & EA & G & $0.5 \backslash 0.44$ & 5.54 & 0.019 & $1.26(1.04-1.52)$ & 0.01 & $1.29(1.06-1.57)$ & 0.013 \\
\hline & $\mathrm{MjD}$ & $\mathrm{AA}$ & G & $0.35 \backslash 0.29$ & 8.05 & 0.005 & $1.35(1.10-1.67)$ & 0.008 & $1.33(1.08-1.63)$ & 0.006 \\
\hline & $\mathrm{MjD}$ & EA & G & $0.51 \backslash 0.44$ & 5.70 & 0.017 & $1.30(1.05-1.62)$ & 0.015 & $1.31(1.05-1.63)$ & 0.013 \\
\hline
\end{tabular}

$A A$, African Americans; $E A$, European Americans. $A D$, alcohol dependence; $C D$, cocaine dependence; $O D$, opioid dependence; $M j D, M a r i j u a n a$ dependence. $P_{\text {obs, }}$ observed $P$ values using Pearson's $C$ i-square tests; $P_{\text {adj, }}$ adjusted $P$ values using multivariable logistic regression analyses after adjustment for sex, age and ancestry proportion under the additive model; $P_{\mathrm{emp}}$, empirical $P$ values using permutation-based tests to correct for multiple testing. RA, reference alleles; $95 \% \mathrm{Cl}, 95 \%$ confidence interval.

RGS17 SNPs (rs9397578-rs7750874-rs503366-rs610614rs545323) (Block I in Figure 2) were associated with all four dependence traits $\left(0.002 \leq P_{\text {obs }} \leq 0.024\right)$. The association between GATTC (potentially a risk haplotype) with OD and GTTCT (potentially a protective haplotype) with $\mathrm{MjD}$ remained significant after correction for multiple testing by permutation tests (GATTC with OD: $P_{\text {empirical }}=0.026 ;$ GTTCT with $\mathrm{MjD}: P_{\text {empirical }}$ $=0.048)$. Two haplotypes (CCT and TGT) comprised of alleles of three RGS17 SNPs (rs9371276-rs1933258rs9397585) (Block II in Figure 2) and one haplotype (CC) comprised of alleles of two RGS17 SNPs (rs6931160-rs1281962) (Block III in Figure 2) were only nominally associated with $\mathrm{OD}$ or $\mathrm{MjD}(0.021 \leq$ $\left.P_{\text {obs }} \leq 0.042\right)$. In EAs, three haplotypes, GTCTT comprised of alleles of five RGS17 SNPs (rs9397578rs7750874-rs503366-rs610614-rs545323) (Block I in Figure 2), CCCC comprised of alleles of four RGS17 SNPs (rs9371276-rs1933258-rs9397585-rs685826) (Block II in Figure 2) and CC comprised of alleles of two RGS17 SNPs (rs6931160-rs1281962) (Block III in Figure 2) were associated with one or more of these four dependence phenotypes $\left(0.004 \leq P_{\text {obs }} \leq 0.044\right)$; only the association of CCCC (potentially a risk haplotype) with OD withstood permutation-based multiple testing correction $\left(P_{\text {empirical }}=0.028\right)$. Detailed haplotype analysis results are presented in Additional file 1: Tables $\mathrm{S} 3$ and S4.

\section{Transcription factor binding sites and correlation of genotypes with expression}

RGS17 promoter SNP rs596359, which was strongly associated with multiple SD traits in both AAs and EAs, was predicted to be located in the binding site of transcription factor AML1a (core binding site: TGTGGT, corresponding to the $\mathrm{G}$ allele but not the A allele). Logistic regression analysis (assuming an additive model) indicated that genotypes of four RGS17 SNPs (rs9371276, rs9397585, rs6931160, and rs596359, which were significantly associated with one or more SD traits), were significantly associated with RGS17 mRNA expression levels in the YRI (rs9371276: $\mathrm{T}=-2.32, \quad P=0.024$; rs9397585: $\mathrm{T}=-2.05, \quad P=0.045 ; \quad$ rs6931160: $\mathrm{T}=3.13$, $P=0.003 ;$ rs596359: $\mathrm{T}=-3.25, P=0.002)$ or the CEU 


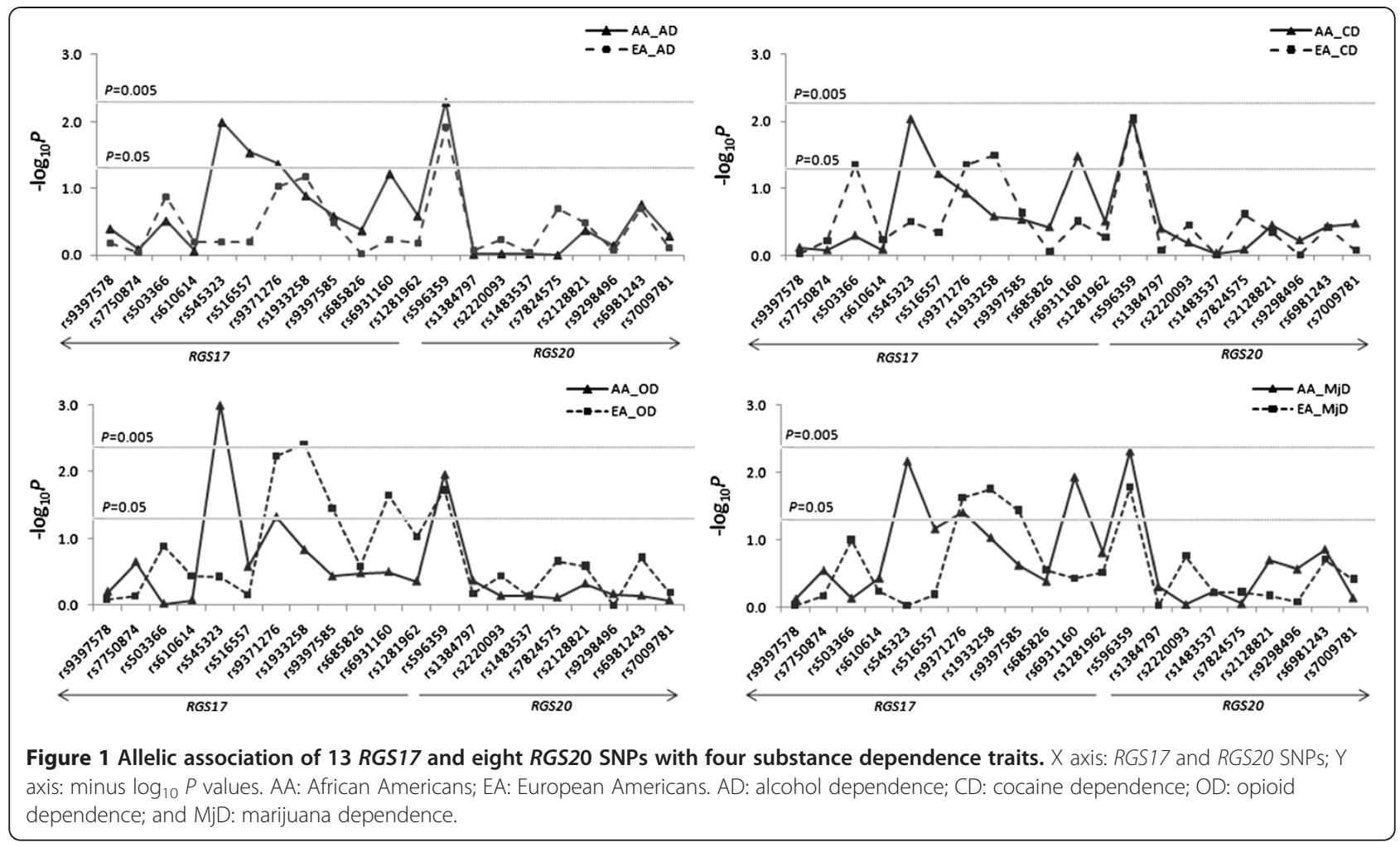

subjects (rs9371276: $\mathrm{T}=-1.65, \quad P=0.105 ; \quad$ rs9397585: $\mathrm{T}=-2.73, \quad P=0.009 ; \quad$ rs6931160: $\mathrm{T}=2.40, \quad P=0.020$; rs596359: $\mathrm{T}=-1.34, P=0.185$ ) (Figure 3 and Additional file 1: Table S5. No significant association was observed between genotypes of the 13 RGS17 SNPs and the expression level of the physically linked gene, OPRM1 (Additional file 1: Table S6).

\section{Discussion}

RGS17 (RGS-Z2) and RGS20 (RGS-Z1) are two members of the RGS-Rz subfamily of GTPase-activating proteins (GAP) that efficiently deactivate GalphazGTP subunits, and thereby turn off the signaling pathway of $\mathrm{G}$ protein-coupled receptors (GPCRs), including opioid receptors. Considering their intimate interactions with opioid receptors (mainly the mu-receptor) and their gene locations (RGS17 is in the vicinity of OPRM1 and RGS20 is in the vicinity of OPRK1), the two genes (RGS17 and RGS20) encoding them are both positional and functional susceptibility candidate loci for SD. We found that multiple RGS17 SNPs were associated with multiple SD phenotypes in both AAs and EAs. However, none of the eight RGS20 SNPs were associated with any of the four dependence traits.

Although variation in RGS17 influences susceptibility to multiple dependence traits in both AAs and EAs, our results suggest that different mechanisms may be operative in some cases. SNPs rs596359 (in the promoter region) and rs6931160 (in intron 1) were associated with at least one of the four dependence traits in both populations. SNPs rs9397585, rs1933258 and rs9371276, which are all located in intron 1 and the same haplotype block (Block II) (Figure 2), were associated with one of the four dependence traits only in EAs. SNPs rs516557 (in intron 2) and rs545323 (in intron 4) were associated with one of the four dependence traits in only AAs (Table 3). Analyses of haplotypes harboring these SNPs supported the individual SNP findings. Haplotypes GATTC and GTTCT, containing alleles (underlined) of SNP rs 545323 (Figure 2, haplotype Block I) were associated with OD and $\mathrm{MjD}$, respectively, only in AAs, after permutation tests to correct for multiple comparisons. Haplotype CCCC, containing alleles (underlined) of the three SNPs (rs9397585, rs1933258 and rs9371276) located in intron 1 and haplotype Block II (Figure 2) was associated with OD only in EAs, after permutation tests to correct for multiple comparisons. These findings suggest that the population-specific associations were dependent on the location of variants in RGS17.

The most statistically significant result was obtained for SNP rs596359, which is located in the promoter region of RGS17. Chi-square tests, logistic regression analyses, and permutation tests all showed a positive association between SNP rs596359 and all four SD phenotypes in both populations (Table 3). Further, metaanalyses that combined data from both AAs and EAs 


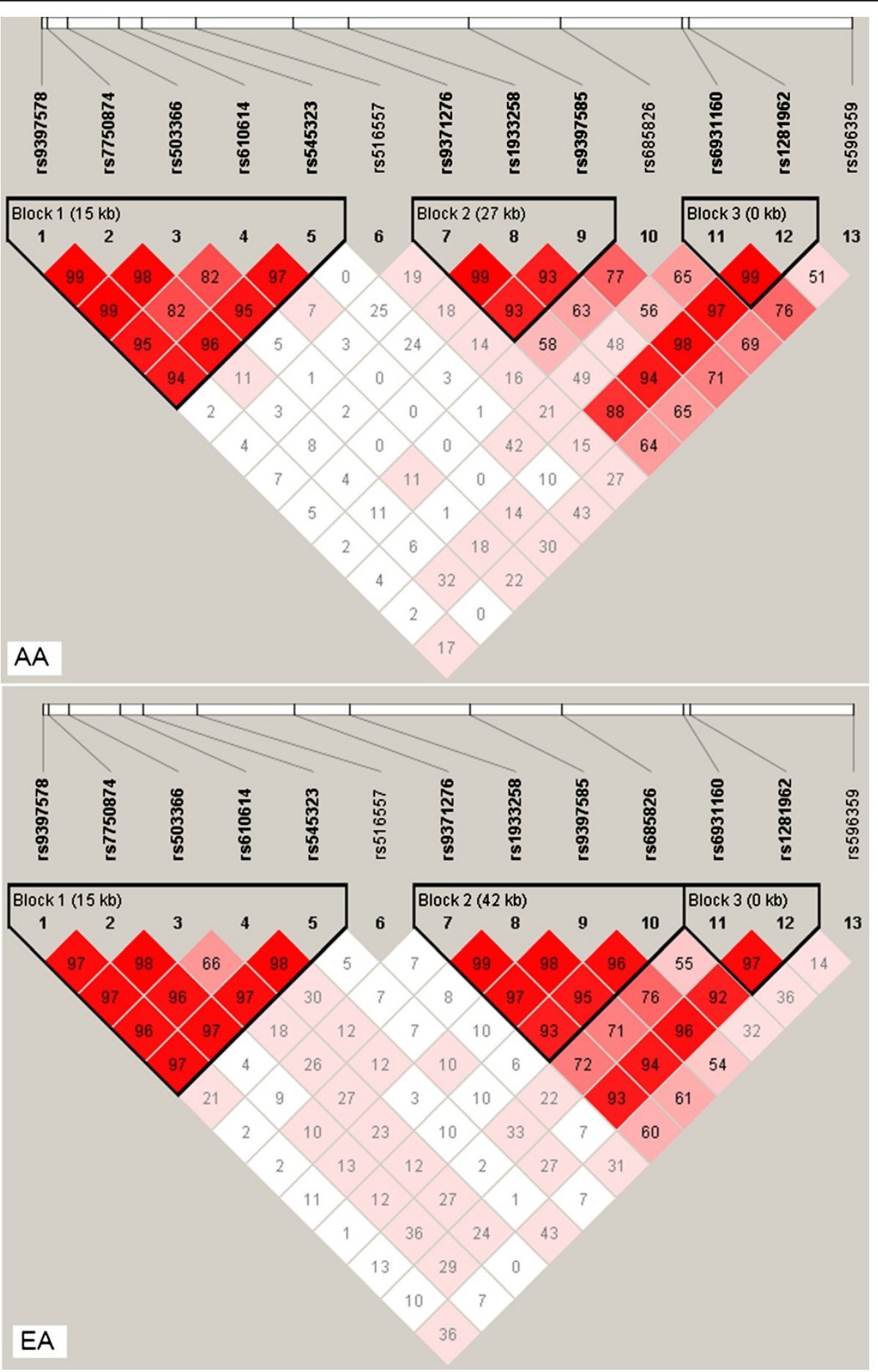

Figure 2 Pairwise linkage disequilibrium (LD) between genotyped RGS17 SNPs. Within each box is the pair-wise estimate of $D^{\prime}$.

showed that SNP rs596359 yielded an odds ratio from 1.28 to 1.33 for risk of all four SD traits (data not shown). Specifically, the G allele of SNP rs596359 was significantly more frequent in cases than in controls in both populations (Additional file 1: Tables S1 and S2). Thus, this promoter variant may increase the risk for SD by influencing RGS17 transcription. To validate the functional effect of this promoter variant on RGS17 
Table 4 Association of RGS17 haplotypes and four substance dependence (SD) traits

\begin{tabular}{|c|c|c|c|c|c|c|}
\hline LD Blocks & Haplotypes & Phenotypes & Frequencies & $x^{2}$ & $P_{o b s}$ & $P_{e m p}$ \\
\hline (AAs) & & & (Case/control) & & & \\
\hline \multirow[t]{8}{*}{ RGS17_I } & GATTC & $A D$ & $0.053 \backslash 0.032$ & 5.09 & 0.024 & 0.319 \\
\hline & GATTC & $C D$ & $0.053 \backslash 0.032$ & 5.41 & 0.020 & 0.267 \\
\hline & GATTC & $\mathrm{OD}$ & $0.067 \backslash 0.032$ & 9.25 & 0.002 & 0.026 \\
\hline & GATTC & $\mathrm{MjD}$ & $0.057 \backslash 0.032$ & 5.95 & 0.015 & 0.178 \\
\hline & GTTCT & $A D$ & $0.015 \backslash 0.029$ & 5.83 & 0.016 & 0.222 \\
\hline & GTTCT & $C D$ & $0.016 \backslash 0.029$ & 5.44 & 0.020 & 0.265 \\
\hline & GTTCT & OD & $0.010 \backslash 0.029$ & 6.65 & 0.010 & 0.106 \\
\hline & GTTCT & MjD & $0.010 \backslash 0.029$ & 8.44 & 0.004 & 0.048 \\
\hline \multirow[t]{3}{*}{ RGS17_II } & $\mathrm{CCT}$ & OD & $0.056 \backslash 0.032$ & 4.49 & 0.034 & 0.375 \\
\hline & TGT & $\mathrm{OD}$ & $0.437 \backslash 0.491$ & 4.16 & 0.042 & 0.436 \\
\hline & TGT & $\mathrm{MjD}$ & $0.440 \backslash 0.491$ & 4.35 & 0.037 & 0.405 \\
\hline RGS17_III & CC & $\mathrm{MjD}$ & $0.528 \backslash 0.472$ & 5.35 & 0.021 & 0.240 \\
\hline LD Blocks & Haplotypes & Phenotypes & Frequencies & $x^{2}$ & $P_{\text {obs }}$ & $P_{e m p}$ \\
\hline (EAs) & & & (Case/Control) & & & \\
\hline \multirow[t]{3}{*}{ RGS17_I } & GTCTT & $A D$ & $0.211 \backslash 0.258$ & 5.75 & 0.017 & 0.159 \\
\hline & GTCTT & $C D$ & $0.206 \backslash 0.258$ & 7.14 & 0.008 & 0.070 \\
\hline & GTCTT & $\mathrm{OD}$ & $0.210 \backslash 0.258$ & 5.56 & 0.018 & 0.169 \\
\hline \multirow[t]{3}{*}{ RGS17_॥ } & $\mathrm{CCCC}$ & $C D$ & $0.302 \backslash 0.260$ & 4.07 & 0.044 & 0.387 \\
\hline & CCCC & OD & $0.324 \backslash 0.260$ & 8.26 & 0.004 & 0.028 \\
\hline & $\mathrm{CCCC}$ & $\mathrm{MjD}$ & $0.309 \backslash 0.260$ & 3.98 & 0.046 & 0.345 \\
\hline RGS17_III & CC & OD & $0.471 \backslash 0.420$ & 4.56 & 0.033 & 0.317 \\
\hline
\end{tabular}

$A D$, alcohol dependence; $C D$, cocaine dependence; $O D$, opioid dependence; MjD, marijuana dependence.

$P_{\text {obs, }}$ observed $P$ values using Pearson's Chi-squared tests.

$P_{\text {emp }}$, empirical $P$ values using permutation-based tests for multiple testing corrections.

transcription, we analyzed the correlation of rs596359 genotypes and RGS17 mRNA expression levels in lymphoblastoid cell lines from both CEU and YRI subjects recruited for the HapMap project

(http://hapmap.ncbi.nlm.nih.gov/). The G allele of SNP rs596359 showed a dose-related decrease in RGS17 transcription by decreasing mRNA expression levels

(Figure 3). Moreover, bioinformatic analyses indicated that substitution of the A allele for the $G$ allele at rs596359 site generated a transcription binding site in the promoter region of RGS17 for transcription factor AML1a. This transcription factor has a higher affinity for DNA-binding than AML1b, but lacks the putative transcriptional activation domain that is possessed by AML1b. Thus, AML1a dominantly suppresses the transcriptional activity exerted by AML1b [36]. Several other studies have demonstrated that AML1a inhibited erythroid or granulocytic differentiation [37,38]. Based on these findings, we would speculate that rs596359 G allele carriers have lower RGS17 activity and thus greater synaptic neurotransmission and rewarding function mediated by GPCRs such as opioid receptors. To test this hypothesis, the influence of SNP rs596359 on RGS17 promoter activity should be measured using other approaches (e.g., luciferase reporter gene assays).

None of the eight RGS20 SNPs showed significant association with any of the four SD phenotypes in either AAs or EAs. There are three possible explanations for this lack of association. First, the RGS2O SNPs selected for this study may have a minor or undetectable effect on SD. Fine-mapping of this gene could identify variants showing a stronger association with SD traits. Second, RGS20 may have a weak effect on susceptibility to SD due to its being physically linked to OPRK1, which has a less important role than OPRM1 (which is physically linked to RGS17) in mediating the rewarding effects of alcohol or drugs $[17,19]$. Third, similar to OPRK1, which mediates the psychotomimetic effects of some drugs [39], RGS20 may mainly regulate other biological activities than SD. Further studies are warranted to determine whether RGS20 is a susceptibility gene for SD.

The present study has several limitations. First, our finding is limited by the relatively small size of the control sample. Moreover, we did not control for prior genotyping performed on this sample in multiple testing corrections because we were concerned that overly 

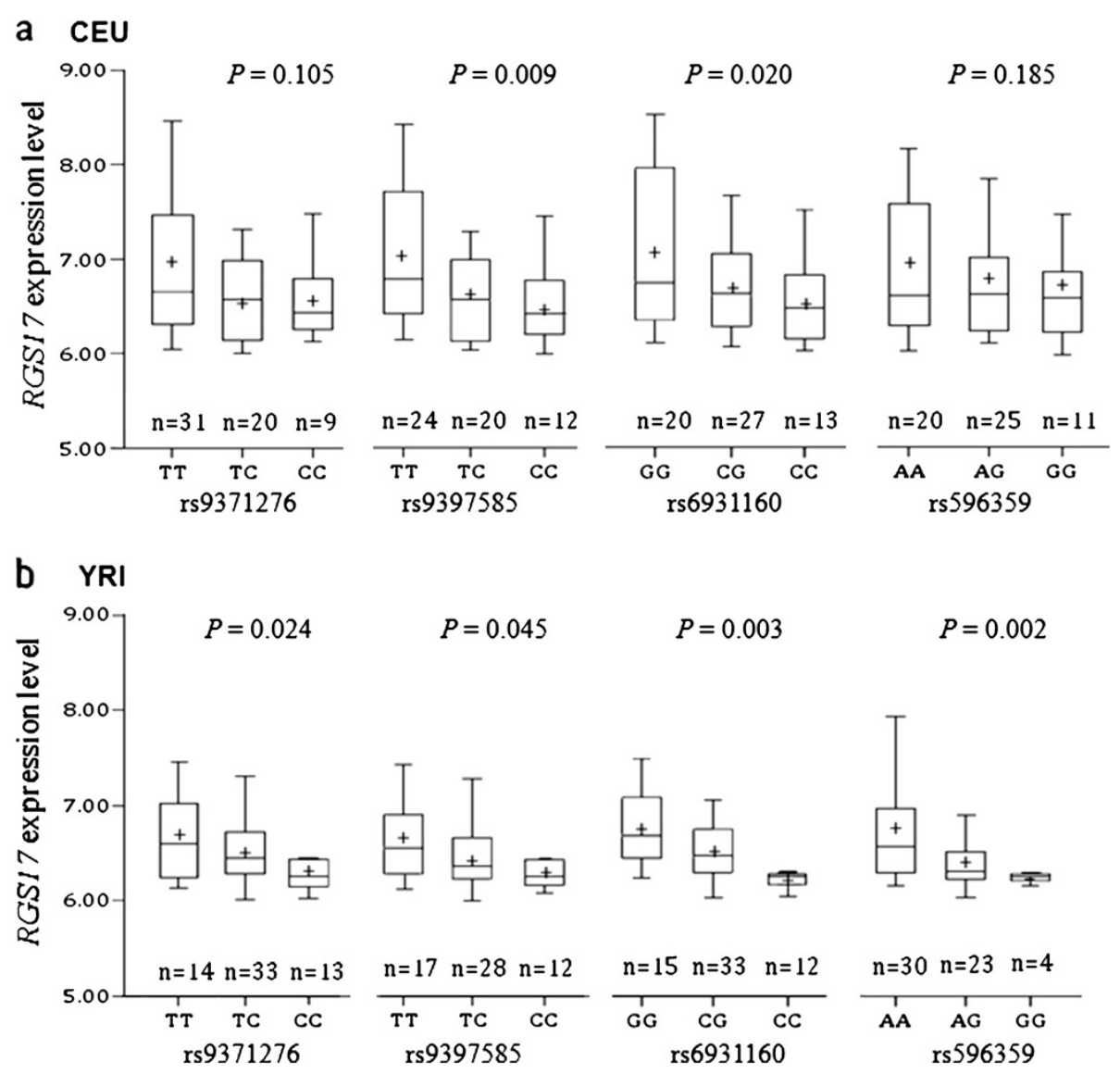

Figure 3 Association of genotypes of four RGS17 SNPs and RGS17 mRNA expression levels. The association between four RGS17 SNPS (rs9371276, rs9397585, rs6931160 and rs596359, which were significantly associated with substance dependence) and RGS17 mRNA expression levels was examined in 60 CEU (a) and 60 YRI (b) unrelated subjects. $P$ values were calculated by linear regression analysis and adjusted by sex. The ends of the vertical lines indicate the minimum and maximum values. The lower hinge of the boxes indicates the $25^{\text {th }}$ percentile, the upper hinge of the boxes indicates the $75^{\text {th }}$ percentile, and the line in the boxes indicates the median value. " + " in the boxes refers to the mean expression level. $\mathrm{X}$ axis: RGS17 SNP genotypes; $Y$ axis: RGS7 mRNA expression levels (mean $\pm \mathrm{SEM}$ ).

conservative results might be obtained. Second, SD frequently co-occurs with Axis I disorders (e.g., depression and anxiety disorders) and Axis II disorders (i.e., personality disorders). Thus, our findings of an association between RGS17 variants and SD may be cofounded by comorbid disorders. Third, given the close relationship between the RGS-Rz (RGS17 and RGS20) and opioid receptor (OPRM1 and OPRK1, respectively) genes, genegene interaction analyses should be conducted. We would speculate that strong gene-gene interaction effects (e.g., of OPRM1 and RGS17) on SD would be detectable. Even though variation at $R G S 20$ did not show significant association with SD in individual gene analysis, interaction effects of that gene with OPRM1 or OPRK1 on $\mathrm{SD}$ risk may exist. Fourth, in this study, we ignored polymorphisms in exonic regions because they are rare in the genes examined. There is only one known SNP rs2295230 (synonymous) in RGS17 exon 2 that had a minor allele frequency greater than 5\% in AA and EA populations. Exonic SNP rs2295230 is in tight LD with intronic SNP rs9371276 (which was included in this study) (CEU: D' $=0.96, \mathrm{r}^{2}=0.92$; YRI: D' $=0.86, \mathrm{r}^{2}=0.54$, using genotyping data from the 1000 Genomes Project). It is also situated close to SNP rs2295230. Thus, exonic SNP rs2295230 was not considered in the present study. As we know, rare variants in coding regions may have a larger impact on disease risk (in the few individuals who carry them) than common non-coding variants (which may have a greater impact at the population level). Recent genome-wide association studies using common genetic variants have identified specific loci and/or genomic regions that contribute to the etiology of certain disorders. However, only a small proportion of the heritability of complex disorders, such as SD, can be accounted for by common variants [40,41]. Therefore, it is necessary to sequence exons of target genes (such as 
RGS17 and RGS20) or perform exomic sequencing using next-generation sequencing technology to identify new rare variants and analyze their association with SD. Fifth, given the incomplete penetrance of susceptibility genes for alcohol or drug dependence in monozygotic twins [42], epigenetic mechanisms should be studied to determine their contribution to SD risk. Altered DNA methylation levels in a number of genes (e.g., OPRM1) have been found in patients with alcohol or opioid dependence $[43,44]$. Altered methylation of RGS17 and RGS2O (especially in their promoter regions) could increase the risk for SD. Therefore, epigenetic studies may provide further evidence about the role of RGS17 and RGS20 in the etiology of SD.

\section{Conclusions}

In summary, we found that RGS17 polymorphisms were associated with multiple SD phenotypes in both AA and EA populations. Our findings suggest that lower transcription levels of $R S G 17$ due to certain genetic variants (e.g., the promoter SNP rs596356) may modulate the reinforcing effects of alcohol or drugs that are mediated by GPCRs such as opioid receptors and thus influence the vulnerability to SD. Given the fact that RGS17 is significantly expressed in striatal regions including the nucleus accumbens and putamen [45], if our findings are validated, RGS17 and its protein product could be good targets for medications to treat SD.

\section{Additional files}

Additional file 1: Supplementary materials

\begin{abstract}
Abbreviations
AD, CD, OD or MjD: Alcohol, cocaine, opioid or marijuana dependence; AIM: Ancestry informative marker; $\mathrm{CMH}$ : The Cochran-Mantel-Haenszel $(\mathrm{CMH})$ test; GAP: GTPase-activating protein; GEO: The Gene Expression Omnibus; GPCR: G protein-coupled receptor; HWE: Hardy-Weinberg equilibrium; OPRM1: The $\mu$-opioid receptor (MOR) gene; OPRK1: The K-opioid receptor (KOR) gene; RGS: Regulator of G-protein signaling protein; SD: Substance (alcohol or drug) dependence; SNP: Single nucleotide polymorphism; TESS: The Transcription Element Search System; TF: Transcription factor.
\end{abstract}

\section{Competing interests}

Dr. Kranzler has received compensation for professional services from the National Institutes of Health (NIAAA and NIDA) and for academic lectures and editorial functions in various scientific venues (including the ACNP). Dr. Kranzler has had consulting arrangements with the following pharmaceutical companies: Alkermes, Gilead, GlaxoSmithKline, Lilly, Lundbeck, Pfizer, and Roche. Dr. Anton has had consulting agreements with the following companies: Eli Lilly, GlaxoSmithKline, Alkermes, Lundbeck, and Roche. Drs. Kranzler and Anton also receive support from the Alcohol Clinical Trials Initiative (ACTIVE), which Eli Lilly, Schering Plough, Lundbeck, Alkermes, GlaxoSmithKline, Abbott, and Johnson \& Johnson support. Drs. Kranzler and Anton report research support from Merck and Dr. Anton from Eli Lilly. Dr. Gelernter reports that he has received compensation for professional services in the previous three years from the following entities: Yale University School of Medicine, Veterans Affairs Healthcare System (VA), and the National Institutes of Health (NIAAA, NIDA, and NIMH), and related to academic lectures and editorial functions in various scientific venues (including the ACNP). Other authors have no conflict of interest to report.

\section{Acknowledgements}

This study was supported by the National Institute of Health (NIH) Grants K99/R00 DA022891 (HZ), R01 DA12690 (JG), R01 AA11330 (JG), R01 DA12849 (JG), R01 AA017535 (JG), R01 DA018432 (HRK), P50 AA012870 (JG\&K), and K05 AA017435 (RFA) and grants from the VA CT MIRECC Center to JG and the Alcoholic Beverage Medical Research Foundation (ABMRF) to $\mathrm{HZ}$.

\section{Author details}

${ }^{1}$ Departments of Psychiatry, Yale University School of Medicine, New Haven, CT, USA. 'Departments of Genetics, Yale University School of Medicine, New Haven, CT, USA. ${ }^{3}$ Departments of Neurobiology, Yale University School of Medicine, New Haven, CT, USA. ${ }^{4}$ VA Connecticut Healthcare System, West Haven, CT, USA. ${ }^{5}$ Department of Psychiatry, University of Pennsylvania Perelman School of Medicine and VISN4 MIRECC, Philadelphia VAMC, Philadelphia, PA, USA. ${ }^{6}$ Department of Psychiatry and Behavioral Sciences, Medical University of South Carolina, Charleston, SC, USA.

\section{Authors' contributions}

$\mathrm{HZ}$ took part in planning, designing and conducting the experiments, collected the data, performed the data analysis and drafted the manuscript. FW helped performing the data analysis and drafting the manuscript. HRK, RFA and JG contributed to sample collection and helped draft the manuscript. All authors read and approved the final manuscript.

Received: 28 December 2011 Accepted: 16 May 2012

Published: 16 May 2012

\section{References}

1. Tsuang MT, Lyons MJ, Meyer JM, Doyle T, Eisen SA, Goldberg J, True W, Lin $\mathrm{N}$, Toomey R, Eaves L: Co-occurrence of abuse of different drugs in men: the role of drug-specific and shared vulnerabilities. Arch Gen Psychiatry 1998, 55(11):967-972

2. Kendler KS, Jacobson KC, Prescott CA, Neale MC: Specificity of genetic and environmental risk factors for use and abuse/dependence of cannabis, cocaine, hallucinogens, sedatives, stimulants, and opiates in male twins. Am J Psychiatry 2003, 160(4):687-695.

3. Lachman HM: An overview of the genetics of substance use disorders. Curr Psychiatry Rep 2006, 8(2):133-143.

4. Li MD, Burmeister M: New insights into the genetics of addiction. Nat Rev Genet 2009, 10(4):225-231.

5. De Vries $L$, Zheng B, Fischer T, Elenko E, Farquhar MG: The regulator of $G$ protein signaling family. Annu Rev Pharmacol Toxicol 2000, 40:235-271.

6. Sierra DA, Gilbert DJ, Householder D, Grishin NV, Yu K, Ukidwe P, Barker SA, He W, Wensel TG, Otero G, Brown G, Copeland NG, Jenkins NA, Wilkie TM: Evolution of the regulators of $\mathrm{G}$-protein signaling multigene family in mouse and human. Genomics 2002, 79(2):177-185.

7. Ross EM, Wilkie TM: GTPase-activating proteins for heterotrimeric $\mathrm{G}$ proteins: regulators of $G$ protein signaling (RGS) and RGS-like proteins. Annu Rev Biochem 2000, 69:795-827.

8. Elenko E, Fischer T, Niesman I, Harding T, McQuistan T, Von Zastrow M, Farquhar MG: Spatial regulation of Galphai protein signaling in clathrin-coated membrane microdomains containing GAIP. Mol Pharmacol 2003, 64(1):11-20.

9. Trinklein ND, Aldred SF, Hartman SJ, Schroeder DI, Otillar RP, Myers RM: An abundance of bidirectional promoters in the human genome. Genome Res 2004, 14(1):62-66.

10. Garzon J, Rodriguez-Munoz M, Lopez-Fando A, Sanchez-Blazquez P: The RGSZ2 protein exists in a complex with mu-opioid receptors and regulates the desensitizing capacity of $\mathrm{Gz}$ proteins. Neuropsychopharmacology 2005, 30(9):1632-1648.

11. Ajit SK, Ramineni S, Edris W, Hunt RA, Hum WT, Hepler JR, Young KH: RGSZ1 interacts with protein kinase $\mathrm{C}$ interacting protein $\mathrm{PKCl}-1$ and modulates mu opioid receptor signaling. Cell Signal 2007, 19(4):723-730.

12. Garzon J, Rodriguez-Munoz M, Lopez-Fando A, Garcia-Espana A, SanchezBlazquez P: RGSZ1 and GAIP regulate mu- but not delta-opioid receptors in mouse CNS: role in tachyphylaxis and acute tolerance. Neuropsychopharmacology 2004, 29(6):1091-1104

13. Town T, Abdullah L, Crawford F, Schinka J, Ordorica PI, Francis E, Hughes P, Duara R, Mullan M: Association of a functional mu-opioid receptor allele (+118A) with alcohol dependency. Am J Med Genet 1999, 88(5):458-461. 
14. Schinka JA, Town T, Abdullah L, Crawford FC, Ordorica PI, Francis E, Hughes P, Graves AB, Mortimer JA, Mullan M: A functional polymorphism within the mu-opioid receptor gene and risk for abuse of alcohol and other substances. Mol Psychiatry 2002, 7(2):224-228.

15. Kim SG, Kim CM, Kang DH, Kim YJ, Byun WT, Kim SY, Park JM, Kim MJ, Oslin DW: Association of functional opioid receptor genotypes with alcohol dependence in Koreans. Alcohol Clin Exp Res 2004, 28(7):986-990.

16. Bart G, Kreek MJ, Ott J, LaForge KS, Proudnikov D, Pollak L, Heilig M: Increased attributable risk related to a functional mu-opioid receptor gene polymorphism in association with alcohol dependence in central Sweden. Neuropsychopharmacology 2005, 30(2):417-422.

17. Zhang H, Luo X, Kranzler HR, Lappalainen J, Yang BZ, Krupitsky E, Zvartau E, Gelernter J: Association between two \{micro\}-opioid receptor gene (OPRM1) haplotype blocks and drug or alcohol dependence. Hum Mol Genet 2006, 15(6):807-819.

18. Xuei X, Dick D, Flury-Wetherill L, Tian HJ, Agrawal A, Bierut L, Goate A, Bucholz K, Schuckit M, Nurnberger J Jr, Tischfield J, Kuperman S, Porjesz B, Begleiter H, Foroud T, Edenberg HJ: Association of the kappa-opioid system with alcohol dependence. Mol Psychiatry 2006, 11(11):1016-1024.

19. Zhang H, Kranzler HR, Yang BZ, Luo X, Gelernter J: The OPRD1 and OPRK1 loci in alcohol or drug dependence: OPRD1 variation modulates substance dependence risk. Mol Psychiatry 2008, 13(5):531-543.

20. Franke P, Wang T, Nöthen MM, Knapp M, Neidt H, Albrecht S, Jahnes E, Propping P, Maier W: Nonreplication of association between mu-opioidreceptor gene (OPRM1) A118G polymorphism and substance dependence. Am J Med Genet 2001, 105(1):114-119.

21. Doyle GA, Furlong PJ, Schwebel CL, Smith GG, Lohoff FW, Buono RJ, Berrettini WH, Ferraro TN: Fine mapping of a major QTL influencing morphine preference in $\mathrm{C} 57 \mathrm{BL} / 6$ and $\mathrm{DBA} / 2$ mice using congenic strains. Neuropsychopharmacology 2008, 33(12):2801-2809.

22. Vadasz C, Saito M, Gyetvai B, Mikics E, Vadasz C: Scanning of five chromosomes for alcohol consumption loci. Alcohol 2000, 22(1):25-34.

23. Yalcin B, Willis-Owen SA, Fullerton J, Meesaq A, Deacon RM, Rawlins JN, Copley RR, Morris AP, Flint J, Mott R: Genetic dissection of a behavioral quantitative trait locus shows that Rgs 2 modulates anxiety in mice. Nat Genet 2004, 36(11):1197-1202.

24. Leygraf A, Hohoff C, Freitag C, Willis-Owen SA, Krakowitzky P, Fritze J, Franke $P$, Bandelow B, Fimmers R, Flint J, Deckert J: Rgs 2 gene polymorphisms as modulators of anxiety in humans?. J Neural Transm 2006, 113(12):19211925.

25. Talkowski ME, Seltman H, Bassett AS, Brzustowicz LM, Chen X, Chowdari KV, Collier DA, Cordeiro Q, Corvin AP, Deshpande SN, Egan MF, Gill M, Kendler KS, Kirov G, Heston LL, Levitt P, Lewis DA, Li T, Mirnics K, Morris DW, Norton N, O'Donovan MC, Owen MJ, Richard C, Semwal P, Sobell JL, St Clair D, Straub RE, Thelma BK, Vallada $H$, et al: Evaluation of a susceptibility gene for schizophrenia: genotype based meta-analysis of RGS4 polymorphisms from thirteen independent samples. Biol Psychiatry 2006, 60(2):152-162.

26. Li D, He L: Association study of the G-protein signaling 4 (RGS4) and proline dehydrogenase (PRODH) genes with schizophrenia: a metaanalysis. Eur J Hum Genet 2006, 14(10):1130-1135.

27. Pierucci-Lagha A, Gelernter J, Feinn R, Cubells JF, Pearson D, Pollastri A, Farrer L, Kranzler HR: Diagnostic reliability of the Semi-structured Assessment for Drug Dependence and Alcoholism (SSADDA). Drug Alcohol Depend 2005, 80(3):303-312.

28. American Psychiatric Association: Diagnostic and Statistical Manual of Mental Disorders. 4th edition. Washington DC.

29. Shi MM, Myrand SP, Bleavins MR, de la Iglesia FA: High throughput genotyping for the detection of a single nucleotide polymorphism in NAD(P)H quinone oxidoreductase (DT diaphorase) using TaqMan probes. Mol Pathol 1999, 52(5):295-299.

30. Pritchard JK, Stephens M, Donnelly P: Inference of population structure using multilocus genotype data. Genetics 2000, 155(2):945-959.

31. Yang BZ, Zhao H, Kranzler HR, Gelernter J: Practical population group assignment with selected informative markers: characteristics and properties of Bayesian clustering via STRUCTURE. Genet Epidemio/ 2005, 28(4):302-312

32. Xie P, Kranzler HR, Poling J, Stein MB, Anton RF, Brady K, Weiss RD, Farrer L, Gelernter J: Interactive effect of stressful life events and the serotonin transporter 5-HTTLPR genotype on posttraumatic stress disorder diagnosis in 2 independent populations. Arch Gen Psychiatry 2009, 66 (11):1201-1209.

33. Purcell S, Neale B, Todd-Brown K, Thomas L, Ferreira MA, Bender D, Maller J, Sklar P, de Bakker PI, Daly MJ, Sham PC: PLINK: a tool set for whole-genome association and population-based linkage analyses. Am J Hum Genet 2007, 81(3):559-575.

34. Barrett JC, Fry B, Maller J, Daly MJ: Haploview: analysis and visualization of LD and haplotype maps. Bioinformatics 2005, 21(2):263-265.

35. Gabriel SB, Schaffner SF, Nguyen H, Moore JM, Roy J, Blumenstiel B, Higgins J, DeFelice M, Lochner A, Faggart M, Liu-Cordero SN, Rotimi C, Adeyemo A, Cooper R, Ward R, Lander ES, Daly MJ, Altshuler D: The structure of haplotype blocks in the human genome. Science 2002, 296(5576): 2225-2229.

36. Tanaka T, Tanaka K, Ogawa S, Kurokawa M, Mitani K, Yazaki Y, Shibata Y, Hirai $\mathrm{H}$ : An acute myeloid leukemia gene, AML1, regulates transcriptional activation and hemopoietic myeloid cell differentiation antagonistically by two alternative spliced forms. Leukemia 1997, 11(Suppl 3):299-302.

37. Tanaka T, Tanaka K, Ogawa S, Kurokawa M, Mitani K, Nishida J, Shibata Y, Yazaki $Y$, Hirai H: An acute myeloid leukemia gene, AML1, regulates hemopoietic myeloid cell differentiation and transcriptional activation antagonistically by two alternative spliced forms. EMBO J 1995, 14(2):341-350

38. Niitsu N, Yamamoto-Yamaguchi Y, Miyoshi H, Shimizu K, Ohki M, Umeda M, Honma Y: AML1a but not AML1b inhibits erythroid differentiation induced by sodium butyrate and enhances the megakaryocytic differentiation of K562 leukemia cells. Cell Growth Differ 1997, 8(3):319-326.

39. Pfeiffer A, Brantl V, Herz A, Emrich HM: Psychotomimesis mediated by kappa opiate receptors. Science 1986, 233(4765):774-776.

40. Maher B: Personal genomes: The case of the missing heritability. Nature 2008, 456(7218):18-21.

41. Conrad DF, Pinto D, Redon R, Feuk L, Gokcumen O, Zhang Y, Aerts J, Andrews TD, Barnes C, Campbell P, Fitzgerald T, Hu M, Ihm CH, Kristiansson K, Macarthur DG, Macdonald JR, Onyiah I, Pang AW, Robson S, Stirrups K, Valsesia A, Walter K, Wei J, Wellcome Trust Case Control Consortium, Tyler-Smith C, Carter NP, Lee C, Scherer SW, Hurles ME: Origins and functional impact of copy number variation in the human genome. Nature 2010, 464(7289):704-712.

42. Goldman D, Oroszi G, Ducci F: The genetics of addictions: uncovering the genes. Nat Rev Genet 2005, 6(7):521-532

43. Nielsen DA, Yuferov V, Hamon S, Jackson C, Ho A, Ott J, Kreek MJ: Increased OPRM1 DNA methylation in lymphocytes of methadone-maintained former heroin addicts. Neuropsychopharmacology 2009, 34(4):867-873.

44. Hillemacher T: Biological mechanisms in alcohol dependence-new perspectives. Alcohol Alcohol 2011, 46(3):224-230.

45. Larminie C, Murdock P, Walhin JP, Duckworth M, Blumer KJ, Scheideler MA, Garnier M: Selective expression of regulators of G-protein signaling (RGS) in the human central nervous system. Brain Res Mol Brain Res 2004, 122(1):24-34.

doi:10.1186/1744-9081-8-23

Cite this article as: Zhang et al:: Variation in regulator of G-protein signaling 17 gene (RGS17) is associated with multiple substance dependence diagnoses. Behavioral and Brain Functions 2012 8:23.

\section{Submit your next manuscript to BioMed Central and take full advantage of:}

- Convenient online submission

- Thorough peer review

- No space constraints or color figure charges

- Immediate publication on acceptance

- Inclusion in PubMed, CAS, Scopus and Google Scholar

- Research which is freely available for redistribution 